\title{
Comparing Properties of THE 42SiCr Steel AFTer CONVENTIONAl Heat Treatment AND QP Processing
}

\author{
Tomas Janda, Hana Jirkova \& Stepan Jenicek
}
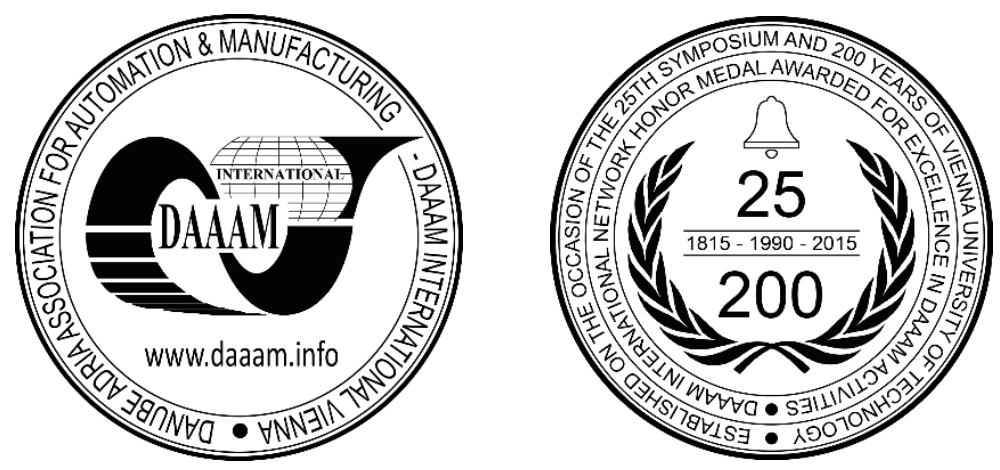

This Publication has to be referred as: Janda, T[omas]; Jirkova, H[ana] \& Jenicek, S[tepan] (2018). Comparing Properties of the 42SiCr Steel After Conventional Heat Treatment and QP Processing, Proceedings of the 29th DAAAM International Symposium, pp.1164-1167, B. Katalinic (Ed.), Published by DAAAM International, ISBN 9783-902734-20-4, ISSN 1726-9679, Vienna, Austria DOI: $10.2507 / 29$ th.daaam.proceedings. 167

\begin{abstract}
To improve the mechanical properties of high strength steels the application of innovative methods is often necessary. One of such technology used in the field of heat treatment (HT) is the quenching and partitioning process. By this method higher content of stabile retained austenite (RA) can be achieved, which increase material ductility while its strength remains only slightly reduced. The experiment compares the mechanical properties of the 42SiCr steel heat treated conventionally or by the QP process. Parameters were designed for both HT modes to achieve approximately the same tensile strength and then the elongations and RA contents were compared. As part of the experiment the metallographic analysis, the X-ray diffraction analysis, hardness measurement and tensile test were performed. The results showed improvement of mechanical properties of the samples treated by QP process. The conventionally treated material (with RA content of $8 \%$ ) showed the elongation of $10 \%$ at the tensile strength of 1980 MPa while the specimen processed by QP reached elongation of $14 \%$ at a tensile strength of $2000 \mathrm{MPa}$ and RA content was also higher $(11 \%)$. On the basis of this knowledge the future research will be focused on the optimization of QP process parameters.
\end{abstract}

Keywords: heat treatment; QP process; high-strength steel

\section{Introduction}

Nowadays there is often a requirement for higher ductility of the high-strength steels. One way how to achieve good combination of high tensile strength and ductility of heat treated steels is a "quenching and partitioning process", by which the elongation of about $10 \%$ at the ultimate tensile strength reaching $2000 \mathrm{MPa}$ can be obtained [1]. The QP process is an innovative HT technology consisting in quenching to the temperature (QT) below $\mathrm{M}_{\mathrm{S}}$ and directly following reheating and holding at the partitioning temperature (PT). After quenching the martensitic microstructure with certain residual austenite content is obtained and increased temperature during partitioning subsequently allows carbon to migrate from supersaturated martensite to retained austenite (RA) [2,3]. This makes RA, that has primarily the form of thin layers between the martensitic slabs and lathes, stable even at room temperature $[4,5]$ and improve the ductility of material. 
For redistribution of carbon, which is crucial for this technology, an appropriate modification of the steel chemical composition is necessary. Usually the addition of silicon suppress the formation of carbides while the manganese and chromium help to stabilize the retained austenite $[6,7]$. However the changes in the steel chemistry also have certain influence on the material and there is a question how much the QP process really contributes to the final properties of the $42 \mathrm{SiCr}$ steel.

Rubešová et. al [8] carried out a research focused on the effect of the quenching and partitioning temperatures on the $42 \mathrm{SiCr}$ steel treated by QP process. Various modes of heat treatment was designed from which the quenching in the $150{ }^{\circ} \mathrm{C}$ molten salt and subsequent partitioning at $250{ }^{\circ} \mathrm{C}$ for 10 minutes was assessed as the best one. Via this treatment the tensile strength of $2080 \mathrm{MPa}$ and elongation of $14 \%$ was achieved. As the second best mode the quenching to the $200{ }^{\circ} \mathrm{C}$ molten salt and the same partitioning as for the previous one was selected. The steel treated this way had the tensile strength of $1995 \mathrm{MPa}$ and elongation of $15 \%$.

In this experiment properties of the $42 \mathrm{SiCr}$ steel heat treated conventionally or by the QP process are compared and the real contribution of the QP process to improvement of the mechanical properties are shown. For both HT modes similar parameters were designed to achieve approximately the same tensile strength. The differences in the elongation and RA content were observed. The QP process parameters were designed according to the above mentioned research [8] i.e. quenching in the $150{ }^{\circ} \mathrm{C}$ molten salt and partitioning at $250{ }^{\circ} \mathrm{C}$ for 10 minutes. On the basis of this experiment the future research will be focused on the optimization of QP process parameters.

\section{Experimental program}

The experimental program was carried out on 42SiCr high-strength steel (Tab. 1). The higher silicon content is used to stabilize the austenite during the phase transformation and thus provides a greater proportion of residual austenite in the microstructure. The starting material for heat treatment was rolled strip of $10 \mathrm{~mm}$ thickness, from which samples with dimension of ca 110x85x10 mm were divided by water jet [9].

The microstructure of the starting rolled strips was mixed, martensitic-bainitic with a small proportion of perlite and free ferrite. Before the heat treatment homogenization of the samples was carried out in an argon-protected furnace at a temperature of $1100{ }^{\circ} \mathrm{C}$ for 4 hours. After this treatment, the structure was pearlitic with a small fraction of ferrite formed at the borders of austenitic grains, and the hardness value reached $281 \mathrm{HV} 10$.

\begin{tabular}{|c|c|c|c|c|c|c|c|c|c|c|c|c|}
\hline $\mathbf{C}$ & $\mathbf{S i}$ & $\mathbf{M n}$ & $\mathbf{P}$ & $\mathbf{S}$ & $\mathbf{C r}$ & $\mathbf{M o}$ & $\mathbf{N i}$ & $\mathbf{A l}$ & $\mathbf{N b}$ & $\begin{array}{c}\mathbf{R m} \\
{[\mathbf{M P a}]}\end{array}$ & $\begin{array}{c}\mathbf{A} \\
{[\mathbf{\%}]}\end{array}$ & $\mathbf{H V 1 0}$ \\
\hline 0,43 & 2,03 & 0,59 & 0,009 & 0,004 & 1,33 & 0,03 & 0,07 & 0,008 & 0,03 & 980 & 15,4 & 281 \\
\hline
\end{tabular}

Table 1. Chemical composition and mechanical properties of the experimental steel 42SiCr after homogenization

The experiment involved two HT modes. The first employing the QP process with quenching to $150{ }^{\circ} \mathrm{C}$ molten salt and subsequent partitioning at $250{ }^{\circ} \mathrm{C}$ for 10 minutes. The conventional mode of HT was designed similarly - the same quenching as in the first (QP) mode, cooling on the air to room temperature and following tempering at $250{ }^{\circ} \mathrm{C}$ for 60 minutes. Heating was conducted in laboratory furnaces without protective atmosphere. The specimens were heated to $950^{\circ} \mathrm{C}$ for $20 \mathrm{~min}$. and then quenched and tempered or partitioned.

The course of heat treatment was recorded using a thermocouple placed in the hole drilled in the side of the plate. Subsequently, metallographic analysis was performed using light and scanning electron microscopy (LM, SEM, respectively) and X-ray diffraction analysis, hardness was measured and static tensile test was performed. The tensile test was carried out on the specimens of circular cross-section with a diameter of $5.0 \mathrm{~mm}$ and an active length of 25 $\mathrm{mm}$. That corresponds to the rated elongation A5, 65. On the fracture surfaces of tensile test specimens the fractography was conducted using scanning electron microscopy (SEM).

\section{Results and discussion}

The microstructures of both specimens consisted of mixture of tempered martensite and lower bainite (Fig. 1 - 4). No differences were found using light and scanning electron microscopy. The precipitation along martensitic laths boundaries was not observed, indicating the suitability of the experimental material to QP process.Using X-ray diffraction analysis the higher RA content was found in the specimen processed by QP (11\%) in comparison with conventionally heat treated specimen ( $8 \%$ ). This resulted in increase in ductility (Tab. 2). 


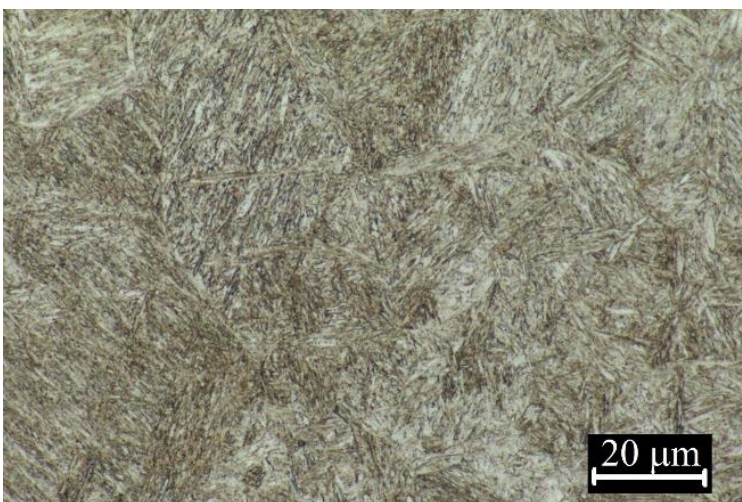

Fig. 1. Microstructure after conventional HT LM micrograph

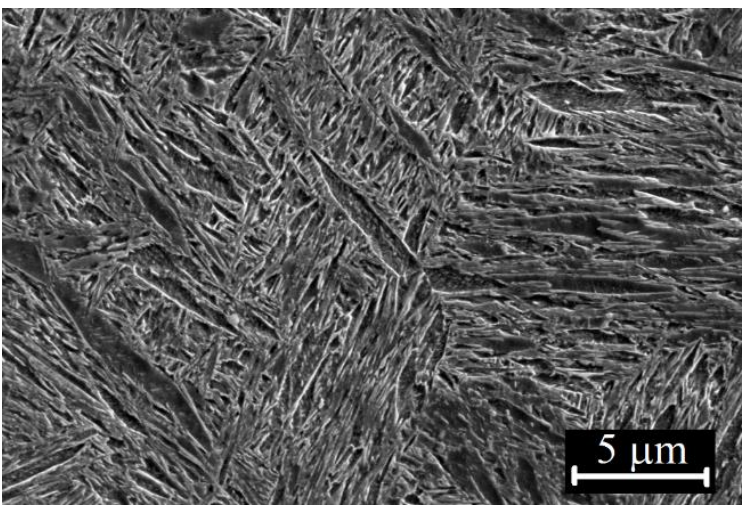

Fig. 3. Microstructure after conventional HT SEM micrograph

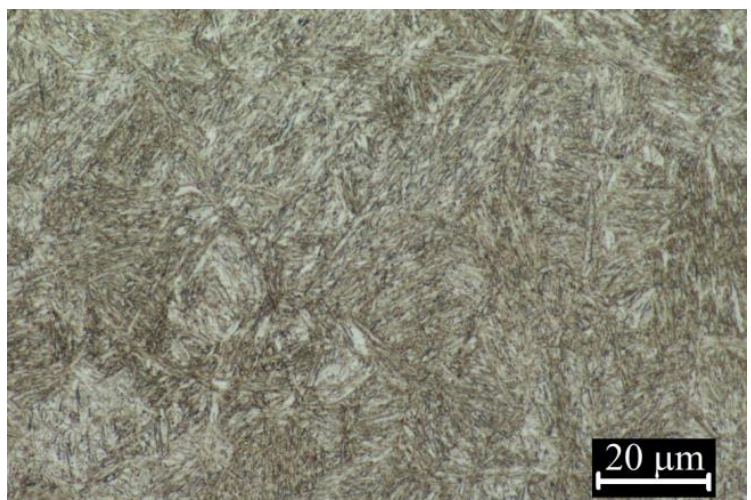

Fig. 2. Microstructure after QP process LM micrograph

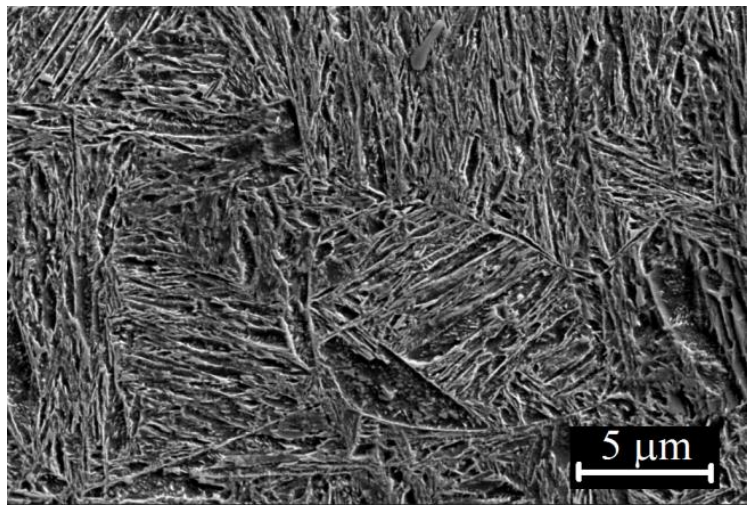

Fig. 4. Microstructure after QP process SEM micrograph

The results of hardness measurement corresponded to the tensile strengths (Tab. 2); the same values were obtained for both specimens (566 HV10, 1,980 MPa and $571 \mathrm{HV} 10,2,000 \mathrm{MPa}$ for conventional HT and QP process, respectively). This is in compliance with the purpose of the experimental program. Higher elongation and lower yield stress were found after QP process in comparison to conventional HT (Fig. 5).

\begin{tabular}{|l|c|c|c|c|c|c|c|c|}
\hline $\begin{array}{l}\text { HT } \\
\text { mode }\end{array}$ & $\begin{array}{l}\text { Austenization } \\
\mathrm{T}_{\mathrm{A}}\left[{ }^{\circ} \mathrm{C}\right] / \mathrm{t}_{\mathrm{A}}[\mathrm{min}]\end{array}$ & $\begin{array}{l}\text { Quenching } \\
\mathrm{T}_{\mathrm{Q}}\left[{ }^{\circ} \mathrm{C}\right]\end{array}$ & $\begin{array}{l}\text { Delay on } \\
\text { air }[\mathrm{min}]\end{array}$ & $\begin{array}{l}\text { Tempering / Partition. } \\
\mathrm{T}_{\mathrm{P}}\left[{ }^{\circ} \mathrm{C}\right] / \mathrm{t}_{\mathrm{P}}[\mathrm{min}]\end{array}$ & $\begin{array}{l}\text { Rm } \\
{[\mathrm{MPa}]}\end{array}$ & $\begin{array}{l}\mathrm{A} \\
{[\%]}\end{array}$ & $\begin{array}{l}\text { Hardness } \\
\text { HV } 10\end{array}$ & $\begin{array}{l}\text { RA } \\
{[\%]}\end{array}$ \\
\hline Convent. & $950 / 20$ & 150 & 30 & $250 / 60$ & 1,980 & 10 & 566 & 8 \\
\hline $\mathrm{QP}$ & $950 / 20$ & 150 & - & $250 / 10$ & 2,000 & 14 & 571 & 11 \\
\hline
\end{tabular}

Table 2. Heat treatment modes and the results of analysis and mechanical tests
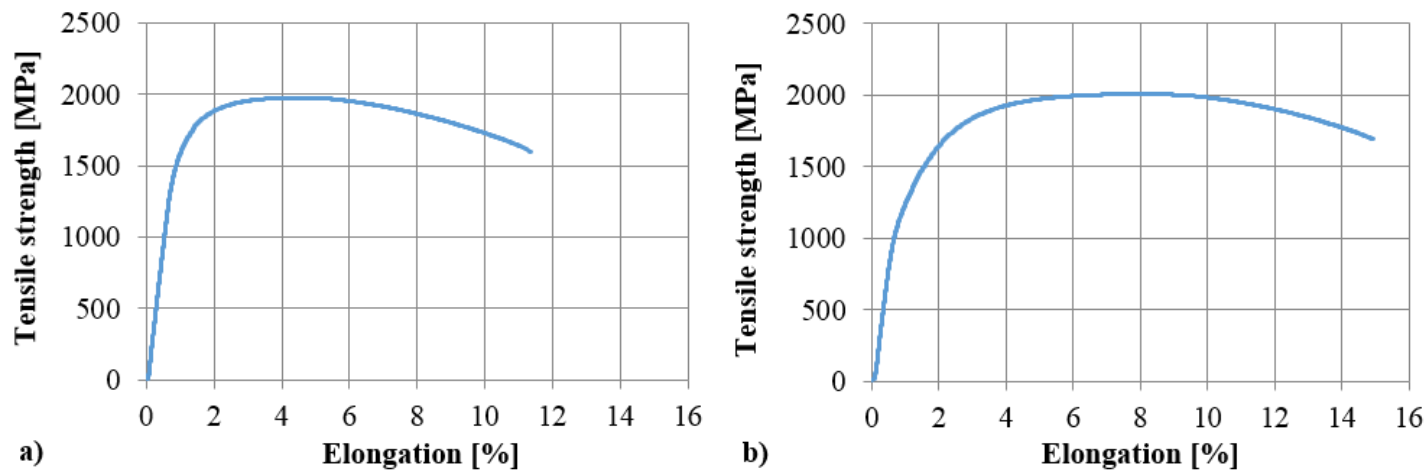

Fig. 5. Graphical representation of tensile test results: a) conventional HT, b) QP process

Fractography carried out using SEM revealed the same features for both specimens. Dimple morphology was observed at fracture surfaces, which indicates ductile transcrystalline fracture (Fig. 6). 


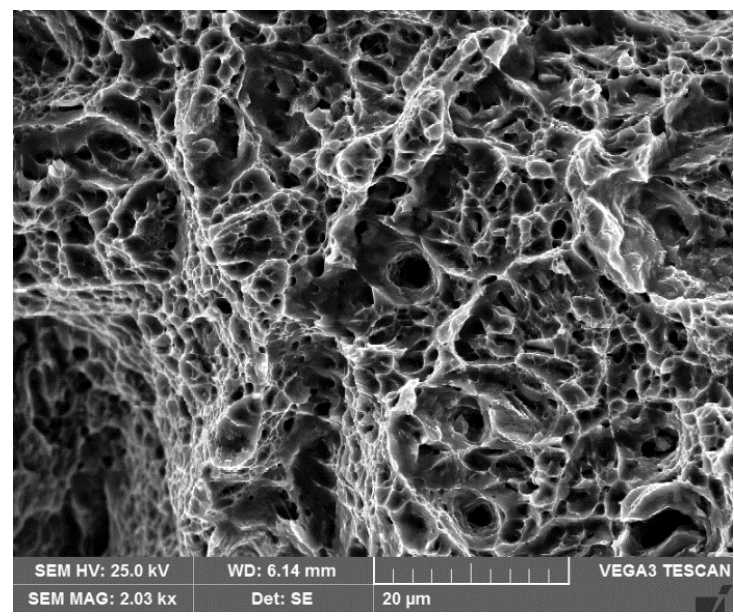

Fig. 6. Fracture surface of QP processed specimen, SEM micrograph

\section{Conclusion}

The experiment compared the mechanical properties of the $42 \mathrm{SiCr}$ steel heat treated conventionally or by the QP process. The results showed improvement of mechanical properties of the samples treated by QP process in comparison to conventionally treated steel, thanks to higher content of RA. The values of ultimate tensile strength and elongation after QP process were as follows: 2,000 MPa and $14 \%$ at the tensile strength of $1980 \mathrm{MPa}$. On the basis of this knowledge the future research will be focused on the optimization of QP process parameters.

\section{Aknowledgement}

The present contribution has been prepared under project LO1502 "Development of the Regional Technological Institute" under the auspices of the National Sustainability Programme I of the Ministry of Education of the Czech Republic aimed to support research, experimental development and innovation.

\section{References}

[1] Edmondsa, D.V.; Hea, K.; Rizzo, F.C.; De Coomanc, B.C.; Matlock, D.K. \& Speer, J.G. (2006). "Quenching and partitioning martensite - A novel steel heat treatment", Materials Science and Engineering: A, Vol. 438-440, pp. 25-34, DOI: 10.1016/j.msea.2006.02.133.

[2] Jenicek, S.; Bublikova, D.; Jirkova, H. \& Kana, J. (2017). Stability of Retained Austenite in High-Strength Martensitic Steels during Cold Deformation, Proceedings of the 28th DAAAM International Symposium, pp.0289-0294, B. Katalinic (Ed.), Published by DAAAM International, ISBN 978-3-902734-11-2, ISSN 17269679, Vienna, Austria, DOI: 10.2507/28th.daaam.proceedings.039

[3] Xu, Y.; Tan, X.; Yang, X.; Hu, Z.; Peng, F.; Wu, D. \& Wang, G. (2014). "Microstructure evolution and mechanical properties of a hot-rolled directly quenched and partitioned steel containing proeutectoid ferrite", Materials Science \& Engineering: A, Vol. 607, pp. 460-475, DOI: 10.1016/j.msea.2014.04.030.

[4] Ibrahim, K.; Bublikova, D.; Jirkova, H. \& Masek, B. (2015). Stabilization of retained austenite in high-strength martensitic steels with reduced Ms temperature, Proceedings of Metal, 2015, Brno, Czech Republic, ISBN: 97880-87294-58-1, p. 1-7, TANGER spol. s r.o., Ostrava.

[5] Pilecek, V.; Jirkova, H. \& Masek B. (2014). "Designing the Q\&P process for experimental steel with $0.47 \%$ carbon content". Advaned materials research, Vol 887-888, 2014, pp. 257-261, DOI: $10.4028 / w w w . s c i e n t i f i c . n e t / A M R .887-888.257$.

[6] Jirkova H.; Kucerova L.; Aisman D. \& Masek B. (2014). „Optimization of the Q-P process parameters for low alloyed steels with $0.2 \%$ C“, Archives of metallurgy and materials, Vol. 59, Issue 3, pp. 1205-1210, DOI: $10.2478 / \mathrm{amm}-2014-0209$.

[7] Jirkova H.; Kucerova L. \& Masek B. (2012). „Effect of quenching and partitioning temperatures in the Q-P process on the properties of AHSS with various amounts of manganese and silicon“, Material science forum, Vol. 706-709, pp. 2734-2739, DOI:10.4028/www.scientific.net/MSF.706-709.2734

[8] Rubesova K.; Vorel I.; Jirkova H. \& Jenicek S. (2018). "Effects of Q\&P process parameters on properties of 42SiCr steel”, Acta Metallurgica Slovaca, Vol. 24, No. 2, pp. 126-133, DOI: 10.12776/ams.v24i2.1063.

[9] Jenicek, S.; Kotesovec, V.; Kalina, T. \& Masek, B. (2016). Use of Waterjet in Manufacturing Test Bars of HighStrength Steels, Proceedings of the 27th DAAAM International Symposium, pp. 0219-0224, B. Katalinic (Ed.), published by DAAAM International, ISBN 978-3-902734-08-2, ISSN 1726-9679, Vienna, Austria, DOI: $10.2507 / 27$ th.daaam.proceedings.032 